\title{
Preclinical Evaluation of a Phosphorothioate Oligonucleotide in the Retina of Rhesus Monkey
}

\author{
Wei-Yong Shen, Kerryn L. Garrett, Chang-Guan Wang, Kun Zhang, Zhi-Zhong Ma, \\ Ian J. Constable, and P. Elizabeth Rakoczy
}

Centre for Ophthalmology and Visual Sciences (WYS, IJC, PER), University of Western Australia, and Department of Molecular Ophthalmology (KLG), Lions Eye Institute, Perth, Western Australia; and Department of Ophthalmology (CGW, KZ, ZZM), General Hospital of Chinese People's Liberation Army, Beijing, People's Republic of China

\begin{abstract}
SUMMARY: Overexpression of vascular endothelial growth factor (VEGF) has been strongly implicated in the development of choroidal neovascularization (CNV) in patients with age-related macular degeneration. In this study, a phosphorothioate oligonucleotide (PS-oligo) targeting both human and rat VEGF ${ }_{165}$ genes upstream of the translation initiation code, named DS135 in this study, was evaluated for its uptake dynamics and retinal tolerance after intravitreal (IV) and subretinal (SR) injections in the rhesus monkey. Intravitreal and SR injections of a fluorescent-labeled DS135 (FL-DS135) resulted in both dose- and time-dependent uptake and persistence, and FL-DS135 remained detectable in the retina for at least 3 weeks after injection. Ophthalmic examination showed transient vitreous haze after IV delivery of a high dose but not with a low dose of FL-DS135. Histologic examination showed no evidence of retinal degeneration with respect to IV delivery. After SR delivery, however, dose-related cellular infiltration, transient residual fluid, and slight distortion of the neuroretina were observed. The biologic efficacy of DS135 was further assessed in a laser-induced CNV model, and development of CNV was determined by fluorescein angiography and histologic examination. Incomplete inhibition of CNV formation was observed after IV and SR injection of DS135, but no statistically significant difference was achieved when compared with dose-matched control of PS-oligo. Analysis of fluorescein angiogram and histologic examination showed less than 30\% incidence of CNV development in this monkey model. Our study demonstrated that PS-oligos can be successfully introduced into the retina, although with potential limitations, after SR delivery. DS135, a PS-oligo targeting the VEGF gene upstream of the translation initiation code, partially inhibited CNV formation. An improved CNV model is necessary for further confirmation of the full therapeutic potency of DS135 before clinical application. (Lab Invest 2002, 82:167-182).
\end{abstract}

A ge-related macular degeneration is the leading cause of visual loss in people more than 65 years old (Young, 1987). The vascular form of age-related macular degeneration is characterized by choroidal neovascularization (CNV) that develops underneath the retina and disrupts the retinal pigment epithelium (RPE) and neurosensory retina, resulting in severe visual loss in a majority of cases (Bressler et al, 1988; Young, 1987). According to the Macular Photocoagulation Study Group guideline, laser photocoagulation is currently the only accepted method to treat CNV but is beneficial for only a small minority of patients with well-demarcated "classic" CNV (Submacular Surgery Trials Pilot Study, 2000a and b). Laser photocoagulation is less dramatic in eyes with new subfoveal CNV, associated with a high rate of CNV persistence and recurrence, and also complicated with marked visual loss because of the inevitable destruction of normal retina by direct or delayed expansion of laser energy

Received September 27, 2001.

This project was partially supported by Meditech Research Ltd. (Australia) and the Dora Lush Postgraduate Research Scholarship, Australian National Health and Medical Research Council (WYS).

Address reprint requests to: Prof. Piroska E. Rakoczy, Department of Molecular Ophthalmology, Lions Eye Institute, Perth, 2 Verdun Street, Nedlands, Western Australia 6009. E-mail: rakoczy@cyllene.uwa.edu.au and irreversible damage to the RPE cells (Shiraga et al, 1998; Submacular Surgery Trials Pilot Study, 2000a and b). Alternatively, photodynamic therapy has been introduced with the aim of occluding the subfoveal CNV with minimal effect on the sensory retina and the RPE (Husain et al, 1999). A recent report from Ophthalmic Technology Assessments showed that photodynamic therapy is effective at reducing the rate of visual loss from predominantly classic CNV at 1 year after treatment; however, this benefit is not significant after 2 years of treatment (Fong, 2000).

During the past five decades researchers have hypothesized that a "vasoformative factor" is responsible for the development of ocular neovascularization (Michaelson, 1948). In recent years there has been extensive research on a specific cytokine, vascular endothelial growth factor (VEGF), as a candidate for this vasoformative factor (Campochiaro, 2000). VEGF is an endothelial cell-specific mitogen that plays a primary role in the angiogenic process. It is expressed before the onset of neovascularization in animal models of proliferative retinopathy and laser-induced CNV (Ishibashi et al, 1997; Shen et al, 1998; Sone et al, 1999). Overexpression of VEGF is also detected in surgically removed samples from patients with diabetic retinopathy and subfoveal CNV (Lip et al, 2000; Lopez et al, 1996). Recent data have demonstrated 
that sole overexpression of VEGF by the RPE cells is sufficient to induce CNV and that suppression of VEGF inhibits the development of neovascularization, indicating that VEGF is the major stimulator for the development of CNV (Kwak et al, 2000; Ozaki et al, 2000; Schwesinger et al, 2001; Spilsbury et al, 2000).

Oligonucleotides are designed to hybridize in a sequence-specific manner to the targeted complementary nucleic acid sequence, thereby inhibiting protein expression (Stein and Cheng, 1993). Almost all oligonucleotides currently being evaluated in clinical trials are phosphorothioate oligonucleotides (PSoligos), in which a single nonbridging oxygen of DNA molecules has been replaced by a sulfur to increase its in vivo stability. Our preliminary experiments have shown successful uptake and persistence of PSoligos in the retina after intravitreal (IV) injection (Rakoczy et al, 1996; Shen et al, 1999). Recently, a series of sequences of the VEGF gene were assessed in an in vitro screening system, and a PS-oligo targeting both human and rat VEGF 165 genes upstream of the translation initiation code, named DS135 in this project, was selected (Garrett et al, 2001). This PS-oligo has been demonstrated to suppress 35\% levels of VEGF production under hypoxic condition in vitro and inhibit a laser-induced CNV via IV injection in the rat (Garrett et al, 2001). In this article, we provide further preclinical information on DS135 using the rhesus monkey, aiming to evaluate its intraocular safety and biologic efficacy in human-like retina, with a further direction to achieve therapeutic inhibition of CNV in humans.

\section{Results}

\section{Ophthalmic Examinations}

This study involved 56 eyes of 28 rhesus monkeys (Table 1). The first step of this project was to investigate the intraocular safety of DS135 after IV and subretinal (SR) injections with varying doses (Table 2). There was no apparent complication directly related to IV and SR surgeries. Transient conjunctival irritation was noted on the day after operation, but this usually cleared within 2 to 3 days. All injected eyes demonstrated clear corneas and lenses. However, vitreous opacity was observed in two of four eyes that received a high dose of fluorescent-labeled DS135 (FL-DS135), demonstrated as a greenish vitreous cavity by indirect ophthalmoscopy (Fig. 1A, Table 2). When re-examined at 3 weeks after injection, however, the vitreous opacity disappeared and translucence was restored in one eye (Fig. 1B), whereas another one still showed vitreous haze (Table 2). The vitreous opacity was not observed in the eyes injected with a low dose of FL-DS135 (Fig. 1, C and D; Table 2).

$\mathrm{SR}$ injection of $50 \mu \mathrm{l}$ of solution induced a local retinal detachment involving the fovea, which extended evenly out to the temporal vascular arcade with a size of about $6000 \mu \mathrm{m}$ in diameter (Fig. 2, A and C). At 1 week after injection, none of the three eyes injected with balanced salt solution (BSS) demonstrated residual SR fluid. However, residual SR fluid was observed in all five eyes that received the high dose (50 $\mu \mathrm{l}, 0.75 \mathrm{nmol} / \mu \mathrm{l})$ of DS135 and in two of four eyes the received the low dose $(50 \mu \mathrm{l}, 0.075 \mathrm{nmol} / \mu \mathrm{l})$ of DS135 (Fig. 2, A and C; Table 2). Although the SR fluid had apparently been absorbed at 3 weeks after injection, the area of the macula that was elevated by the SR injection was still visible, and also the neuroretina and RPE were slightly disturbed by the injected DS135 solution (Fig. 2, B and D).

\section{Uptake Dynamics of DS135 in the Retina}

Considering the fact that the retinal lipofuscin-like autofluorescence usually complicates the use of fluorescent techniques (Fig. 3, $\mathrm{A}$ and $\mathrm{C}$ ), we successfully eliminated the lipofuscin-like autofluorescence by incubation of sections with Sudan Black B $0.5 \%$ solution (Fig. 3, B and D). Treatment with Sudan Black B slightly reduced the intensity of FL-DS135, however, the reduction of labeled fluorophore was far less dramatic than that for the lipofuscin-like compound. Reduction of autofluorescence provides a reasonable compromise between lipofuscin-like autofluorescence and clearer interpretation of distribution and persistence of FL-DS135 in the retina (Fig. 3, B and D).

The uptake dynamics of FL-DS135 after IV and SR injections have been summarized in Table 3. Intraocular delivery of high doses of FL-DS135 (50 $\mu \mathrm{l}, 7.5$ $\mathrm{nmol} / \mu \mathrm{l}$ for IV and $0.75 \mathrm{nmol} / \mu \mathrm{l}$ for SR injections, respectively) resulted in a high intensity of fluorescent signal across the retina at 1 week after injection, demonstrated as fluorescent signal in the RPE and throughout all neural layers of the retina (Fig. 4, A and E). Injections of lower doses of DS135 led to much weaker fluorescent signal in the retina, however, positive signal was consistently detected in the RPE layer (Fig. 4, C and G). The uptake of FL-DS135 was both dose and time dependent. At 3 weeks after injection, time-matched photographic exposures indicated that the fluorescent signal in eyes that received high doses of FL-DS135 became weaker and speckled when compared with that at 1 week after injection (Fig. 4, B and F). With low doses of oligos, only a very faint and irregular fluorescent signal was detected (Fig. 4, D and $\mathrm{H})$.

\section{Toxicology by Light Microscopy}

Evaluation of toxicology was concentrated at the levels of the neuroretina, the SR space, and the RPE layer, aiming to look for evidence of cellular infiltration, neuroretinal degeneration, and disturbed RPE cells. The results are summarized in Table 4. Histologic examination, either from frozen or paraffin-embedded sections, revealed no abnormality in the retina after IV injection (Fig. 5, A, C, and E; Table 4). SR injection of BSS slightly disturbed the RPE cells, demonstrated as enlarged and hyperpigment RPE cells at the site of injection. Cellular infiltration was minor and infrequent (Fig. 5B, Table 4). SR administration of DS135, however, induced dose-dependent cellular infiltration in the SR space (Fig. 5, D and F; Table 4). Disruption of 


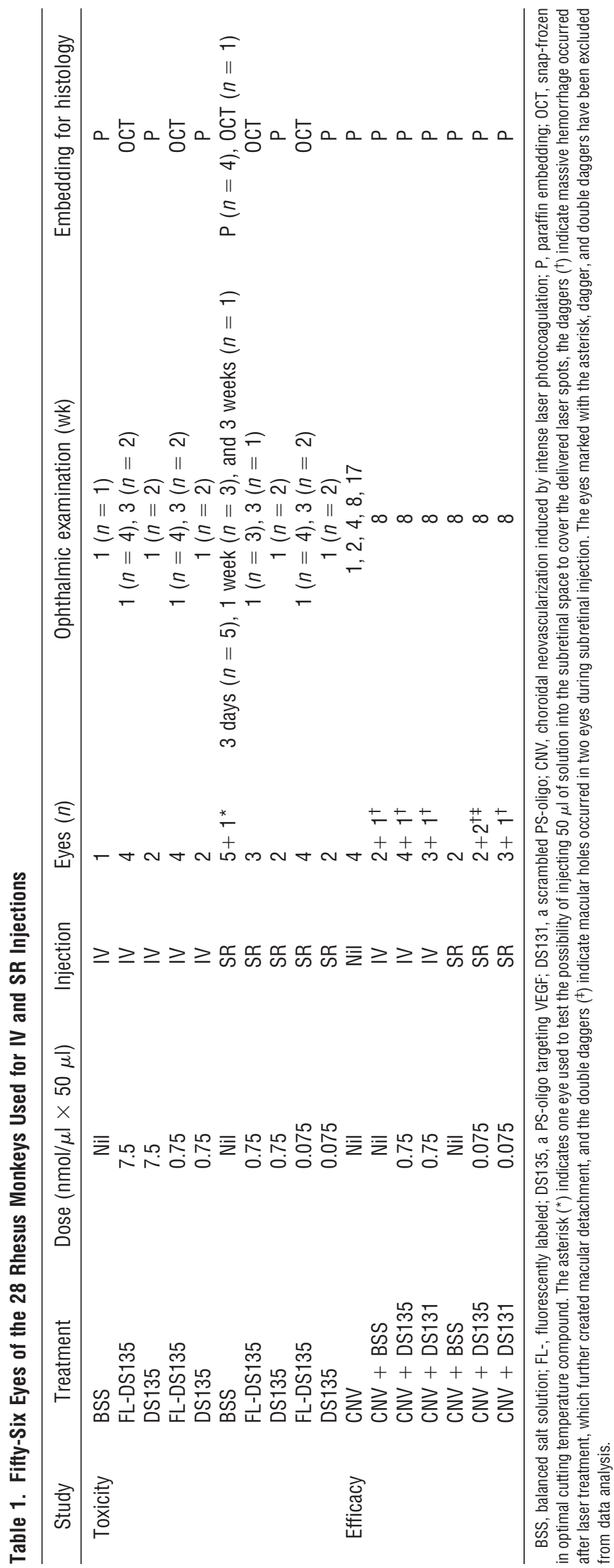


Table 2. Ophthalmic Examinations After IV and SR Injections in the Rhesus Monkey

\begin{tabular}{|c|c|c|c|c|c|c|c|}
\hline \multirow[b]{2}{*}{ Injection } & \multirow[b]{2}{*}{ Solution } & \multirow[b]{2}{*}{$\begin{array}{c}\text { Dose } \\
(\mathrm{nmol} / \mu \mathrm{l} \times 50 \mu \mathrm{l})\end{array}$} & \multirow[b]{2}{*}{$\begin{array}{l}\text { Eyes } \\
(n)\end{array}$} & \multicolumn{4}{|c|}{ Ophthalmic examinations } \\
\hline & & & & $\begin{array}{l}\text { Haze } \\
\text { vitreous }\end{array}$ & Residual SR fluid & $\begin{array}{l}\text { Disturbed RPE } \\
\text { and retina } \\
\text { (on site) }\end{array}$ & $\begin{array}{c}\text { Disturbed RPE } \\
\text { and retina } \\
\text { (off site) }\end{array}$ \\
\hline \multirow[t]{5}{*}{ IV } & BSS & Nil & 1 & - & Nil & Nil & - \\
\hline & FL-DS135 & 7.5 & 4 & $2 / 4^{*} 1 / 2^{\dagger}$ & Nil & Nil & - \\
\hline & DS135 & 7.5 & 2 & - & Nil & Nil & - \\
\hline & FL-DS135 & 0.75 & 4 & - & Nil & Nil & - \\
\hline & DS135 & 0.75 & 2 & - & Nil & Nil & - \\
\hline \multirow[t]{4}{*}{ SR } & BSS & Nil & 3 & - & $0 / 3^{*}$ & $3 / 3(+,+,+)$ & $0 / 3$ \\
\hline & FL-DS135 & 0.75 & 3 & - & $3 / 3^{*}(++,++,++) ; 0 / 1^{\dagger}$ & $3 / 3(+,+,+)$ & $1 / 3(++)$ \\
\hline & DS135 & 0.75 & 2 & - & $2 / 2^{*}(+,+)$ & $1 / 2(+)$ & $1 / 2(+)$ \\
\hline & FL-DS135 & 0.075 & 4 & - & $2 / 4^{\star}(+,+) ; 0 / 2^{\dagger}$ & $4 / 4(+,+,+,+)$ & $2 / 4(+,+)$ \\
\hline
\end{tabular}

BSS, balanced salt solution; FL-, fluorescently labeled; DS135, a PS-oligo targeting VEGF. RPE, retinal pigment epithelium. The terms "on site" and "off site" are defined as at the site of injection and at an area away from the needle penetration site, respectively. The subretinal residual fluid and disturbed RPE were graded as follows: - no residual fluid (or no RPE and retinal disturbance); + minor subretinal fluid, visible by 3-dimensional observation (or slightly disturbed RPE and retina); ++ moderate subretinal fluid, easily recognized by direct observation (or moderately disturbed RPE and retina).

The asterisks $\left(^{*}\right)$ indicate that the eyes were examined at 1 week, and the daggers $\left(^{\dagger}\right)$ indicate that the eyes were examined continuously at 1 and 2 weeks after injection.
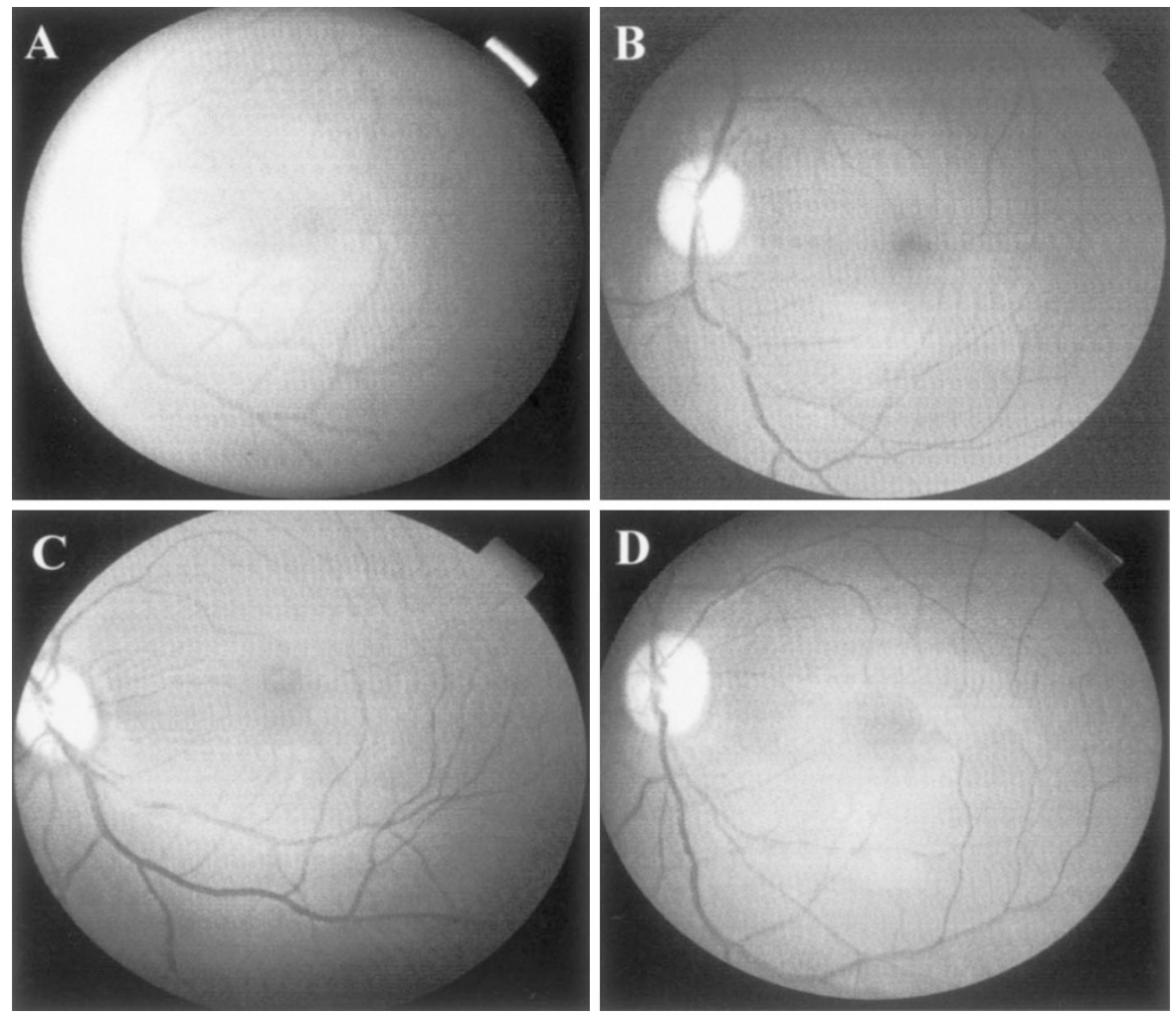

\section{Figure 1.}

Fundus photographs after intravitreal (IV) injection of $50 \mu$ l of fluorescent-labeled DS135 (FL-DS135) at 1 week (A and C) and 3 weeks (B and D) after injection. A and $\mathrm{B}, 7.5 \mathrm{nmol} / \mu \mathrm{l} ; \mathrm{C}$ and $\mathrm{D}, 0.75 \mathrm{nmol} / \mu \mathrm{l}$. Transient vitreous haze was observed at 1 week after the high-dose injection (A).

the photoreceptor outer segments and slight distortion of the neuroretina were also observed (Fig. 5F, Table 4).

\section{Development of CNV After Intense Laser Photocoagulation}

Determined by the presence of fluorescein leakage or pooling at the late phase of fluorescein angiography
(FA), CNV formation was observed at 2 weeks and remained for at least 8 weeks after photocoagulation. Intraocular manipulation, either IV or SR injection of BSS, did not affect the development of CNV (data not shown). However, less than $30 \%$ of laser spots showed CNV-related fluorescein leakage in this monkey model $(23 \%, 26.5 \%, 28.6 \%$, and $27 \%$ at $2,4,6$, and 8 weeks after laser photocoagulation, respective- 

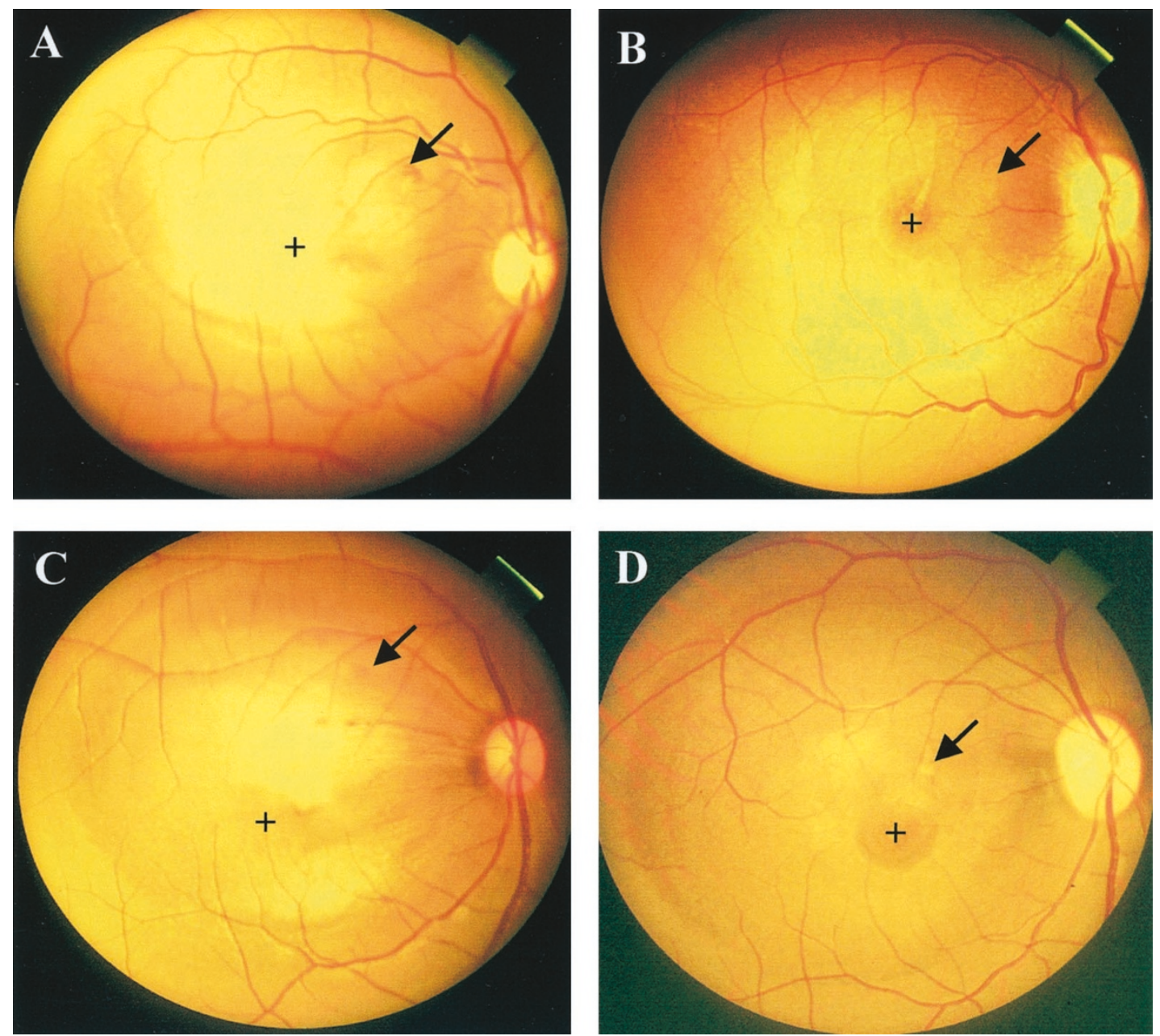

Figure 2.

Fundus photographs after subretinal (SR) injection of $50 \mu \mathrm{l}$ of FL-DS135 at 1 week (A and C) and 3 weeks (B and D) after injection. A and B, $0.75 \mathrm{nmol} / \mu \mathrm{l} ; \mathrm{C}$ and $\mathrm{D}, 0.075 \mathrm{nmol} / \mu \mathrm{l}$. Residual SR fluid existed at 1 week after injection (A and C). Although the SR fluid had apparently been absorbed at 3 weeks after injection, the area of the macula that was elevated by the SR injection was still visible, and the neuroretina and retinal pigment epithelium (RPE) cells were slightly disturbed by the injected DS135 solution (B and D). The plus symbols indicate the central fovea, and the arrows point to the pinpoints of glass-pipette penetration demonstrated as minor depigmentation, respectively.

ly). Although all laser spots were delivered by the same ophthalmologists using the same protocol, CNV formation varied dramatically among individual eyes. Of the eight eyes used to generate the CNV model, four eyes showed no sign of CNV at any laser lesion during the period from 2 to 8 weeks after photocoagulation.

CNV formation was finally examined histologically, showing that new vessels developed between the Bruch's membrane and RPE layer or extending into the SR space. However, $41.7 \%$ of laser lesions showed an intact Bruch's membrane and most of these lesions failed to develop CNV (Fig. 6, A and B). Generally, only $22.1 \%$ of lesions had histologic CNV. These new vessels originated from choriocapillaries and extended in the SR space, forming SR neovascular membrane networks (Fig. 6C).

\section{Effect of DS135 on the Development of CNV}

After laser photocoagulation, six eyes showed massive SR hemorrhage that further created macular detachment. A macular hole occurred in two of these six eyes after SR delivery of PS-oligos, and these six eyes were excluded from data analysis (Table 1). In the other 12 eyes that underwent laser photocoagulation and IV/SR injection of PS-oligos (Table 1), ophthalmic assessment showed no abnormalities on the cornea and lens, nor in the regions of retina away from the injected area (data not shown).

The effect of DS135 on the development of CNV was determined by fluorescein leakage or pooling at the late phase of FA (Figs. 7 and 9). The data obtained from FA were also correlated with the results of histologic examination at 8 weeks, when the project was terminated (Figs. 8 and 10). Intravitreal delivery of DS135 (50 $\mu \mathrm{l}, 0.75 \mathrm{nmol} / \mu \mathrm{l})$ partially inhibited CNV formation in certain eyes. This was mostly demonstrated as decreased intensity of CNV-related fluorescein leakage during FA. However, this inhibition was incomplete and moderate fluorescein-leaking laser spots were still detectable, indicating slight development of CNV networks in these eyes (Fig. 7, B, D, and 

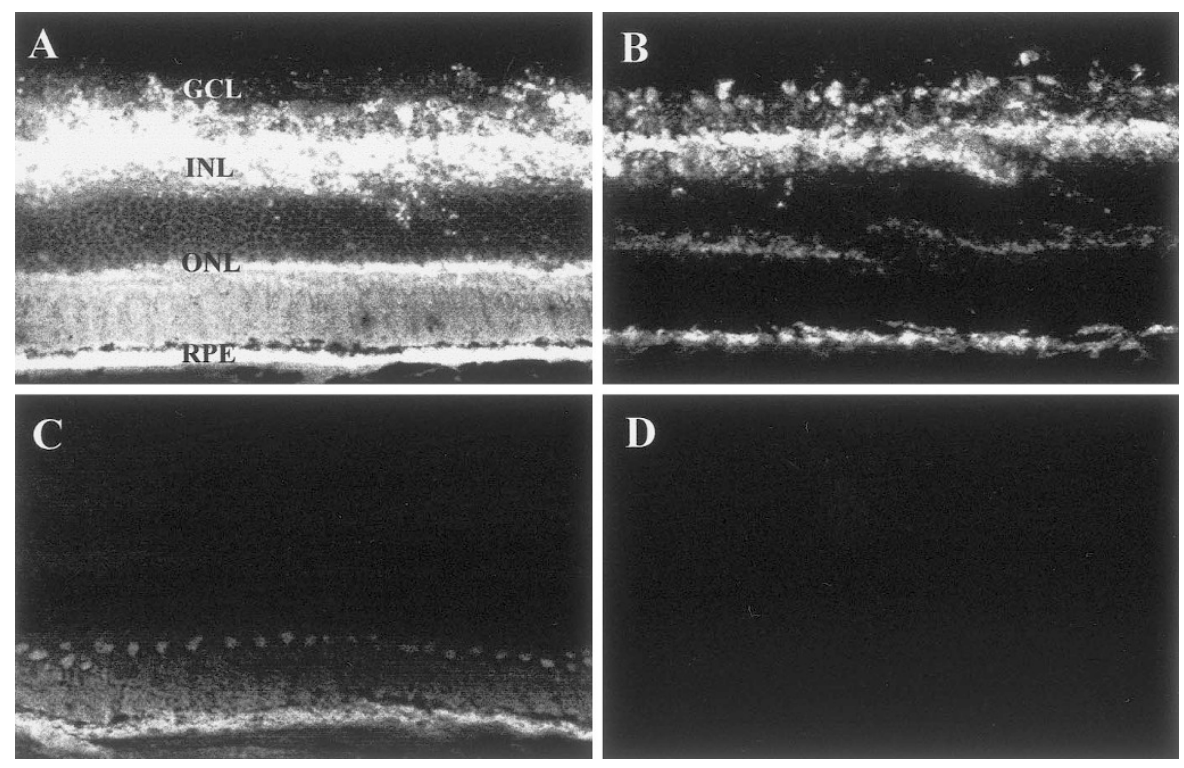

Figure 3.

Reduction of retinal lipofuscin-like autofluorescence. Confocal laser scanning photomicrographs were taken before $(A$ and $C)$ and after (B and D) incubation of cryosections in $0.5 \%$ Sudan Black B solution. Cryosections were obtained from eyes that received IV injection of high-dose FL-DS135 (A and B) or balanced salt solution $(C$ and $D)$ at 1 week after injection. RPE $=$ retinal pigment epithelium; $\mathrm{ONL}=$ outer nuclear layer; INL $=$ inner nuclear layer; $\mathrm{GCL}=$ ganglion cell layer. Original magnifications $(A$ to $D), \times 50$.

Table 3. Distribution and Persistence of a Fluorescently Labeled DS135 in the Retina After IV and SR Injections in the Rhesus Monkey

\begin{tabular}{cccccccc}
\hline & & & & \multicolumn{4}{c}{ Fluorescent Signal } \\
\cline { 5 - 7 } Injection & $\begin{array}{c}\text { Dose } \\
(\mathrm{nmol} / \mu \mathrm{I} \times 50 \mu \mathrm{l})\end{array}$ & $\begin{array}{c}\text { Time } \\
(\mathrm{wk})\end{array}$ & $\begin{array}{c}\text { Eyes } \\
(n)\end{array}$ & GCL & INL & ONL & RPE \\
\hline IV & 7.5 & 1 & 2 & ++ & ++++ & +++ & ++++ \\
& 7.5 & 3 & 2 & + & + & + & ++ \\
& 0.75 & 1 & 2 & + & + & + & ++ \\
SR & 0.75 & 3 & 2 & + & - & - & + \\
& 0.75 & 1 & 2 & ++ & +++ & ++++ & ++++ \\
& 0.75 & 3 & 1 & + & + & + & ++ \\
& 0.075 & 1 & 2 & + & + & + & ++ \\
& 0.075 & 3 & 2 & - & - & + & + \\
\hline
\end{tabular}

Lipofuscin-like autofluorescence was blocked by incubation of cryosections in a $0.5 \%$ Sudan Black B solution for 17 minutes. GCL, ganglion cell layer; INL, inner nuclear layer; ONL, outer nuclear layer. The fluorescent signal was graded by the density and patterns of distribution as follows: - no signal; + weak or moderate but scattered; ++ moderate and evenly distributed; +++ strong and evenly distributed; ++++ very strong and evenly distributed.

F). To compare the effect of DS135 with control PS-oligo DS131, the intensity of fluorescein leakage was graded by semiquantification. Only the laser lesions showing +2 or higher than +2 scores of fluorescein leakage during FA were considered as CNV related (Fig. 8A). After IV injection, no laser lesion showed +3 scores, but $34.4 \%$ of the lesions demonstrated +2 scores of CNV-related fluorescein leakage in the DS135-treated group $(n=4)$. The percentages of laser lesions showing +2 and +3 scores in the DS131-treated group were $20.8 \%$ and $12.5 \%$, respectively $(n=3)$. By semiquantification, no statistically significant difference was achieved between the DS135 and dose-matched control DS131-treated groups when comparing either individual scores $(+2$ or +3 ) or taking scores together ( +2 and +3 scores), as a result of dramatically individual variations in CNV formation and the limited numbers in each group (Fig.
8A). This tendency was further supported by data obtained from histologic examination, showing that $23.8 \%$ and $21.1 \%$ of laser lesions developed histologic CNV in the DS135- and DS131-treated groups, respectively (Fig. 8B).

In the eyes that received SR injection of PS-oligos, the injected solution covered all laser spots, and the SR fluid was completely absorbed at 2 weeks after injection (data not shown). Similar to the results of IV injection, incomplete inhibition of CNV formation was observed in DS135-treated eyes. This was mostly demonstrated as fewer lesions showing +2 and +3 scores of fluorescein leakage in the DS135-treated group (Fig. 9, B, D, and F, and Fig. 10). The percentages of leaking lesions with +2 and +3 scores were $12.5 \%$ and $18.8 \%$ in the DS135-treated group $(n=2)$ and $25 \%$ and $20.8 \%$ in the DS131-treated group $(n=$ 3), respectively (Fig. 10A). By termination of the project 

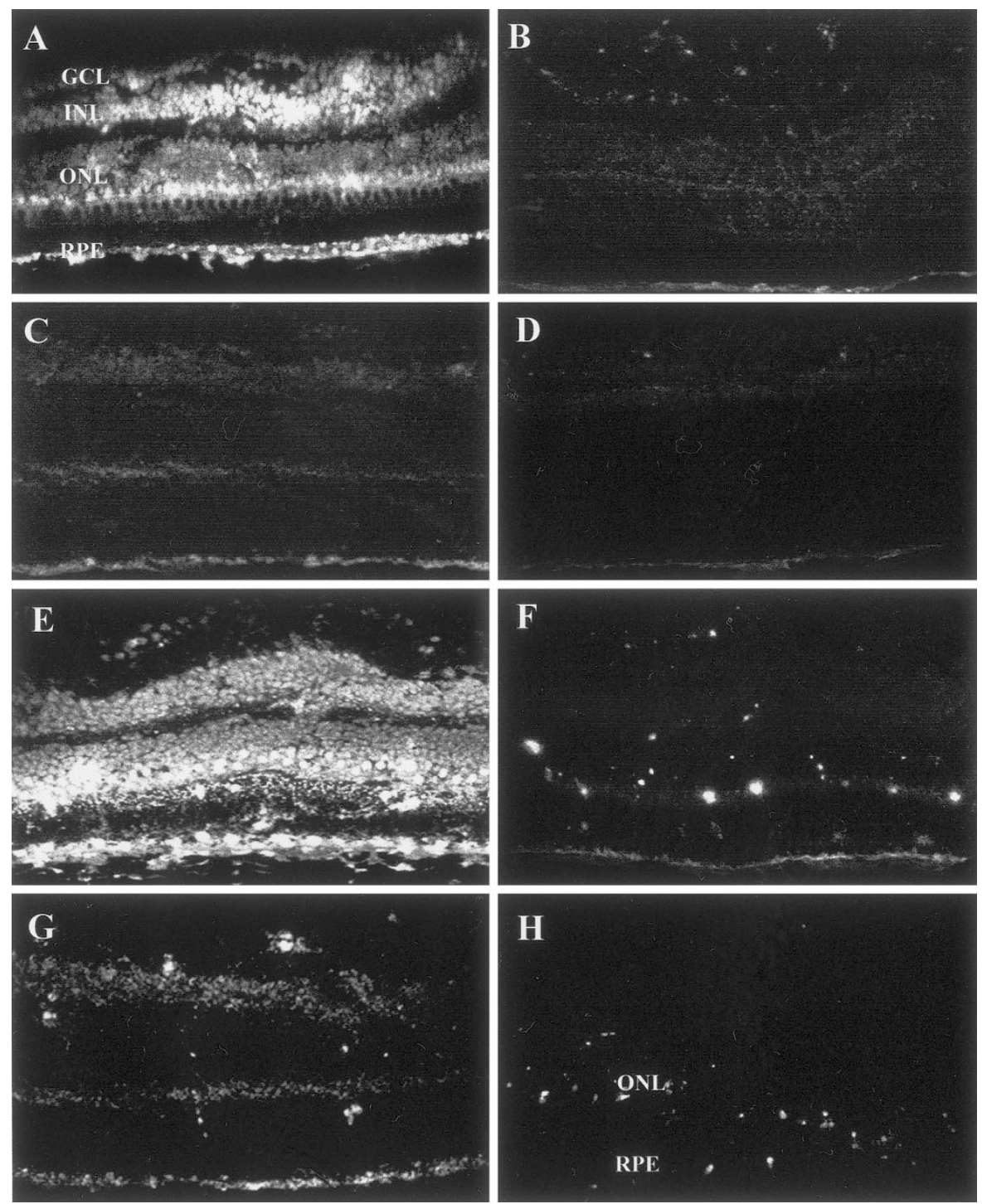

Figure 4.

Uptake dynamics of FL-DS135 after IV ( $A$ to D) and SR ( $E$ to $H$ ) delivery of $50 \mu$ of FL-DS135 at 1 week (A, C, E, and G) and 3 weeks (B, D, F, and H) after injection. $A$ and $B, 7.5 \mathrm{nmol} / \mu \mathrm{l} ; \mathrm{C}$ to $\mathrm{F}, 0.75 \mathrm{nmol} / \mu \mathrm{l} ; \mathrm{G}$ and $\mathrm{H}, 0.075 \mathrm{nmol} / \mu \mathrm{l}$. Delivery of FL-DS135 resulted in dose- and time-dependent distribution in the RPE and neuroretina. $\mathrm{ONL}=$ outer nuclear layer; INL $=$ inner nuclear layer; $\mathrm{GCL}=$ ganglion cell layer. Original magnifications $(\mathrm{A}$ to $\mathrm{H}), \times 50$.

at 8 weeks after treatment, histologic examination showed that $25 \%$ and $31.3 \%$ of laser lesions developed CNV in the DS135- and DS131-treated groups, respectively (Fig. 10B). Again, analysis of the data obtained from FA and histologic examination did not show a statistically significant difference between the DS135- and DS131-treated groups after SR injection ( $>0.41$; Fig. 10).

\section{Discussion}

In this study, we used FL-DS135 to monitor oligonucleotide distribution, persistence, and stability in the retina after IV and SR injections. The retinal lipofuscinlike autofluorescence has been eliminated by incubation of sections with Sudan Black B, thus allowing for an accurate interpretation of the uptake dynamics of FL-DS135 in the eye. In a previous investigation (Shen et al, 1999), we have injected 6-carboxyfluorescein amidite (6-FAM), the fluorescent molecule conjugated to the $5^{\prime}$ terminal nucleotide for labeling DS135. Fluorescent signal in 6-FAM injected eyes completely disappeared at 24 hours after injection. However, fluorescence remained strong for at least 4 weeks in the eyes injected with the labeled PS-oligo, indicating that the fluorescence observed in the eyes that received the labeled PS-oligos is associated with oligonucleotide itself rather than the fluorescent molecule that was used for the labeling (Shen et al, 1999). Using Genescan electrophoresis, we were also able to resolve single nucleotide differences in length, and our results have shown that the oligonucleotide extracted from injected eyes was full length during the period of 2 to 6 weeks, except for minor amounts of $\mathrm{N}-1$ degradation products at 8 and 12 weeks after injection (Shen et al, 1999). 
Table 4. Histologic Examination of the Eyes that Received IV or SR Injection in the Rhesus Monkey

\begin{tabular}{|c|c|c|c|c|c|c|c|c|}
\hline \multirow[b]{2}{*}{ Injection } & \multirow[b]{2}{*}{ Solution } & \multirow{2}{*}{$\begin{array}{c}\text { Dose } \\
(\mathrm{nmol} / \mu \mathrm{l} \times 50 \mu \mathrm{l})\end{array}$} & \multirow{2}{*}{$\begin{array}{c}\text { Eyes } \\
(n)\end{array}$} & \multicolumn{3}{|c|}{ Cellular Infiltration } & \multirow{2}{*}{$\begin{array}{c}\text { Disturbed } \\
\text { RPE }\end{array}$} & \multirow{2}{*}{$\begin{array}{c}\text { Retinal } \\
\text { distortion }\end{array}$} \\
\hline & & & & Vitreous & Retina & SR space & & \\
\hline \multirow[t]{5}{*}{ IV } & BSS & Nil & 1 & - & - & - & - & - \\
\hline & FL-DS135 & 7.5 & 4 & - & - & - & - & - \\
\hline & DS135 & 7.5 & 2 & - & - & - & - & - \\
\hline & FL-DS135 & 0.75 & 4 & - & - & - & - & - \\
\hline & DS135 & 0.75 & 2 & - & - & - & - & - \\
\hline \multirow[t]{5}{*}{ SR } & BSS & Nil & 3 & - & - & $1 / 3(+)$ & $1 / 3(++)$ & $0 / 3$ \\
\hline & FL-DS135 & 0.75 & 3 & - & - & $2 / 2^{*}(+,++)$ & $2 / 2(+,++)$ & $1 / 2(+)$ \\
\hline & DS135 & 0.75 & 2 & - & - & $2 / 2(+++,++++)$ & $1 / 2(++)$ & $1 / 2(++)$ \\
\hline & FL-DS135 & 0.075 & 4 & - & - & $2 / 4(+,+)$ & $2 / 4(+,+)$ & $1 / 4(+)$ \\
\hline & DS135 & 0.075 & 2 & - & - & $1 / 2(+)$ & $0 / 2$ & $1 / 2(+)$ \\
\hline
\end{tabular}

BSS, balanced salt solution; FL-, fluorescently labeled; DS135, a PS-oligo targeting VEGF; DS131, a scrambled PS-oligo. Cellular infiltration was graded according to the number of inflammatory cells per field $(\times 140)$ as follows: - no cellular infiltration; +1 to 5 cells; ++6 to 10 cells; +++11 to 20 cells; and ++++ $>20$ cells. The disturbed RPE was graded as follows: - no RPE disturbance; + proliferating RPE cells but remain one single layer; + + proliferating RPE cells, two layers; and +++ proliferating RPE cells, more than two layers. The asterisk $\left({ }^{*}\right)$ indicates that the maculae was visible microscopically in two of three eyes that received subretinal injection of FL-DS135.

${ }^{a}$ Retinal distortion was evaluated in areas off the pinpoint of SR penetration and graded as - normal, + minor, ++ moderate, and +++ severe changes.

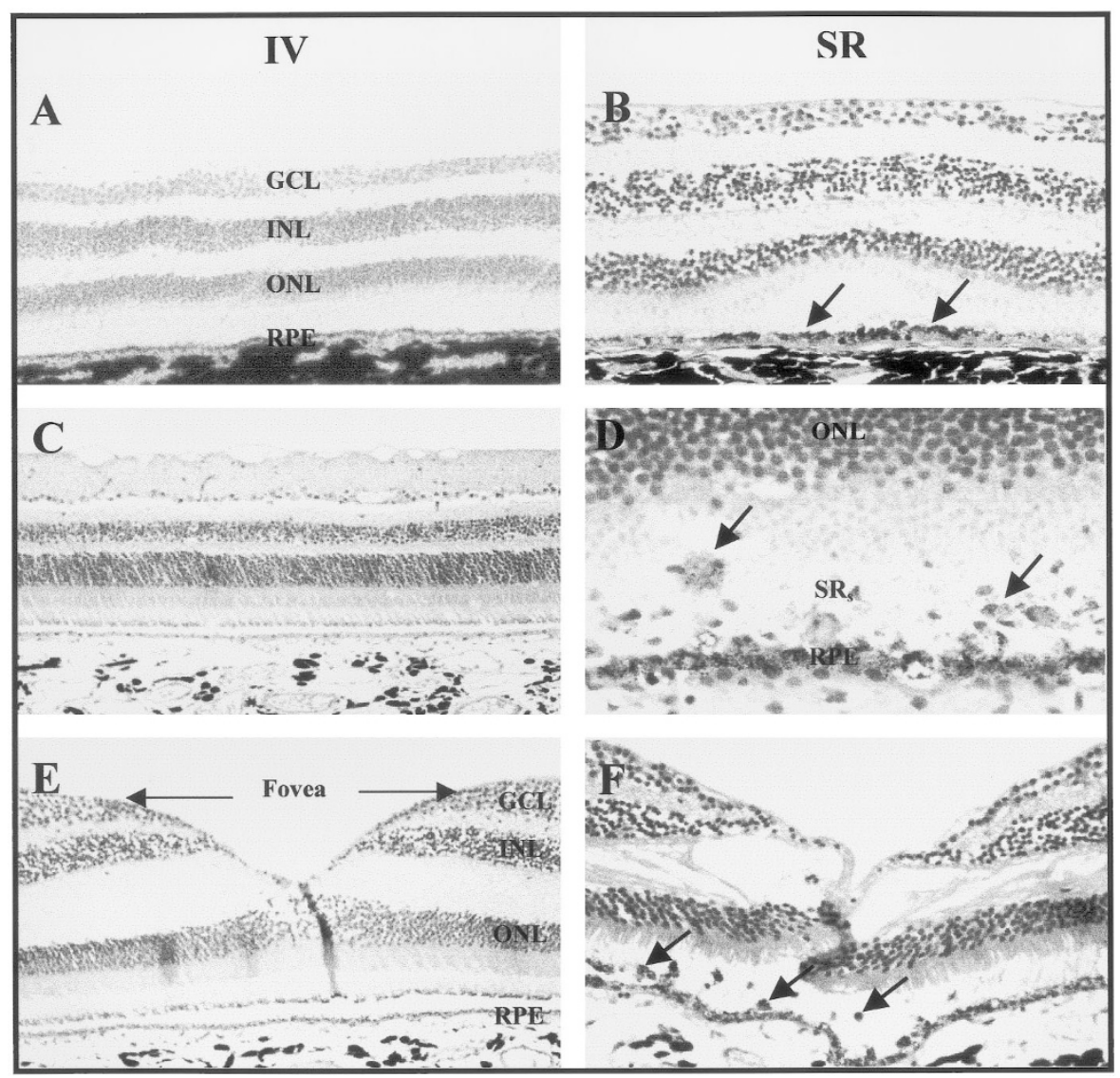

Figure 5.

Histologic examination of eyes that received IV (A, C, and E) and SR (B, D, and F) injections of $50 \mu$ l of test solution. Photomicrographs were taken at the macula $(A, B$, and $D)$, far from the macula $(C)$, and the central fovea ( $E$ and $F$ ), respectively. The arrows in B indicate disturbed RPE and the arrows in $D$ and $F$ indicate inflammatory cells in the subretinal space $\left(\mathrm{SR}_{\mathrm{s}}\right)$. Slight disruption of the photoreceptor outer segments and distortion of the neuroretina were observed in $\mathrm{F}$. A, DS135, $7.5 \mathrm{nmol} / \mu \mathrm{l}, 3$ weeks after injection. B, BSS, 1 week after injection. C-E, DS135, $0.75 \mathrm{nmol} / \mu \mathrm{l}, 1$ week after injection. F, DS135, $0.075 \mathrm{nmol} / \mu \mathrm{l}, 1$ week after injection. $\mathrm{ONL}=$ outer nuclear layer; $\mathrm{INL}=$ inner nuclear layer; $\mathrm{GCL}=$ ganglion cell layer. $\mathrm{A}$ to $\mathrm{F}$, Hematoxylin and eosin staining. Original magnifications $(\mathrm{A}$ to $\mathrm{C}, \mathrm{E}$ and $\mathrm{F})$, $\times 70 ; \mathrm{D}, \times 140$.

In this study, IV injection of a high dose of FL-DS135 $(50 \mu \mathrm{l}, 7.5 \mathrm{nmol} / \mu \mathrm{l})$ resulted in strong fluorescence distribution in the RPE and all neural layers at 1 week after injection, and the uptake dynamics were both dose and time dependent. Although the intensity of the fluorescent signal dramatically declined in the 


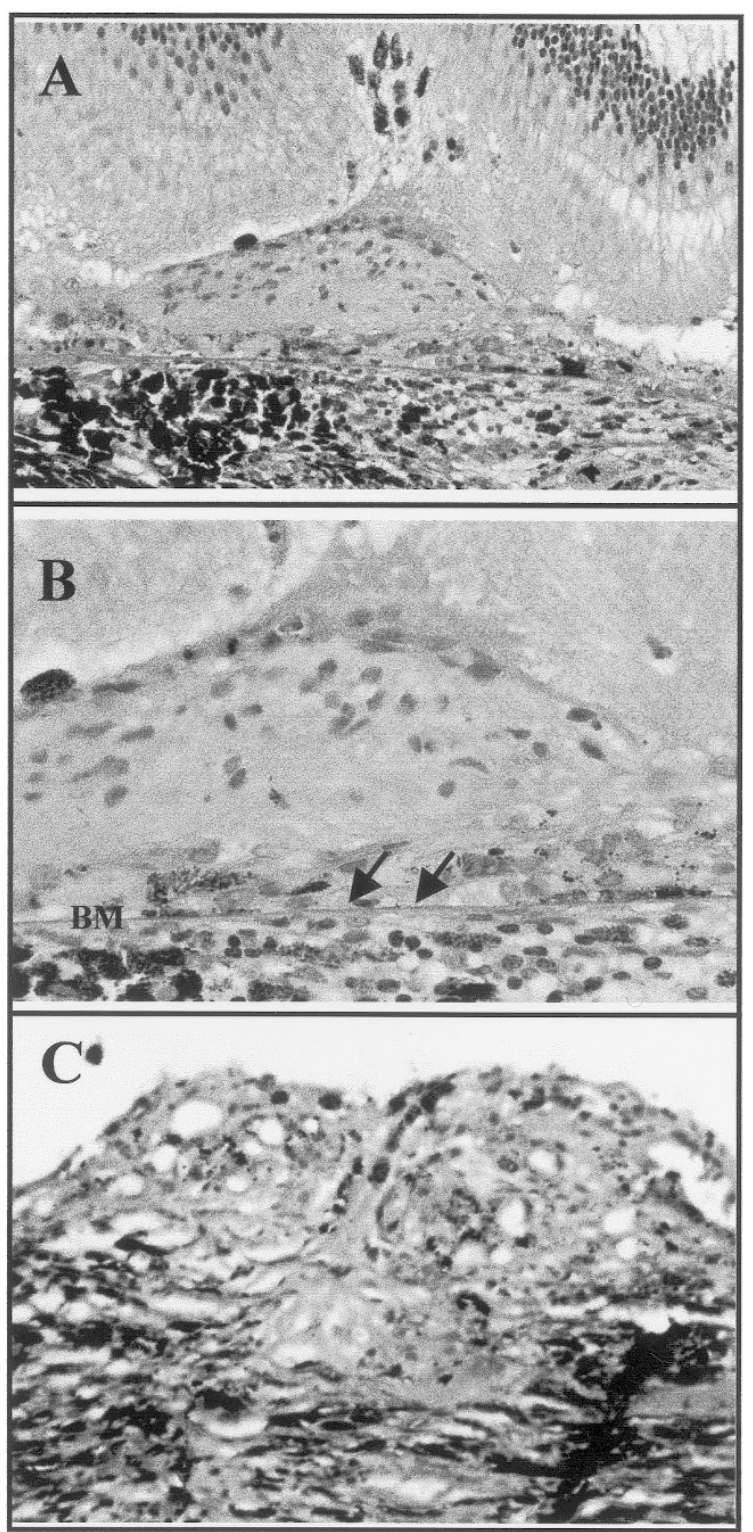

Figure 6.

Development of choroidal neovascularization (CNV) after laser photocoagulation. A, photomicrograph showing SR scar tissue formation of one laser spot and the surrounding retina. $B$, higher magnification of $A$ showing the intact Bruch's membrane (arrows). C, SR neovascular membrane networks originate from the choriocapillaries passing through the broken Bruch's membrane. BM $=$ Bruch's membrane.

neuroretina at 3 weeks after injection, a relatively stronger signal was consistently detected in the RPE layer. This is consistent with previous data obtained from the rat study (Rakoczy et al, 1996; Shen et al, 1999) and also very similar to a previous report that PS-oligos remained detectable for up to 14 days after IV injection in the monkey (Leeds et al, 1998). Although IV injection is a well-established technique and delivery of high doses of PS-oligos resulted in a wide distribution throughout the retina, in the clinical reality, it might be more practical to deliver small doses of PS-oligo into a confined area where the diseased condition exists. In this study, we also investigated the uptake dynamics after SR injection, aiming to explore the feasibility of SR administration of DS135 for the treatment of CNV. To our knowledge, this is the first study to demonstrate successful delivery of PS-oligos through SR injection in the monkey. In this study, the dosages used for SR injection (50 $\mu \mathrm{l}, 0.75$ or 0.075 $\mathrm{nmol} / \mu \mathrm{l})$ were 10 times lower than those used for IV injection ( $50 \mu \mathrm{l}, 7.5$ or $0.75 \mathrm{nmol} / \mu \mathrm{l})$, however, similar or even better uptake dynamics were achieved. Interestingly, comparing SR delivery with IV injection, the actual residence time of FL-DS135 in the retina was not remarkably different. The delivered FL-DS135 remained detectable for up to 3 weeks with both situations, indicating a much slower rate of PS-oligo clearance from the retina when compared with the vitreous. This opens up a real opportunity in the use of SR delivery of small doses of PS-oligos to introduce direct delivery and avoid the short half-life of PS-oligos in the vitreous, thus reducing the global risk of retinal toxicity and minimizing the cost of molecular products.

An important concern before efficacy study is to investigate the intraocular safety. The monkey has a vascularized retina and vitreous volume very similar to those in humans. More importantly, the monkey is the only species of experimental animal who possesses a macula, which is a particularly important issue for evaluation of intraocular safety when the treatment strategy targets this confined area. With the highest dose for IV injection $(50 \mu \mathrm{l}, 7.5 \mathrm{nmol} / \mu \mathrm{l})$, the final concentration in the vitreous cavity is close to those in the rat eye where $2.0 \mu \mathrm{l}$ of 5.0 to $10 \mathrm{nmol} / \mu \mathrm{l}$ PS-oligos were injected but without showing pathogenicity (Shen et al, 1999). This calculation was based on the assumption that the vitreous volume in monkey eye is $1.5 \mathrm{ml}$ and the vitreous volume of rat eye is $50 \mu \mathrm{l}$. After IV delivery in this study, data from histologic examination did not show toxicity to the retina. However, indirect ophthalmoscopy revealed transient vitreous haze with a high dosage $(50 \mu \mathrm{l}, 7.5 \mathrm{nmol} / \mu \mathrm{l})$ of DS135, indicating a possibly transient inflammatory response in the vitreous cavity. To date, most studies have involved IV administration of PS-oligo into the eye (Dvorchik and Marquis, 2000; Flores-Aguilar et al, 1997; Hangai et al, 1998; Leeds et al, 1997, 1998; Ogata et al, 1999; Rakoczy et al, 1996; Robinson et al, 1996; Shen et al, 1999; Stone and Jaffe, 2000). It has been reported that high doses of PS-oligos after IV injection induce cataract, severe inflammatory response, increased intraocular pressure, maculopathy, and permanent retinal damage (Detrick, 2001; Dvorchik and Marquis, 2000; Flores-Aguilar et al, 1997; Stone and Jaffe, 2000). These adverse effects could be serious limitations to the potential use of high doses of PS-oligos by IV injection in humans.

We also investigated the SR administration route, with the aim of introducing direct delivery with reduced doses of DS135. SR injection is a basic and essential procedure during complicated macular surgeries (Submacular Surgery Trials Pilot Study, 2000a and $b$ ). This procedure requires only a pinpoint of retinotomy. A single procedure of SR injection is clinically acceptable provided the delivered DS135 is nontoxic and efficacious. In the present study, al- 

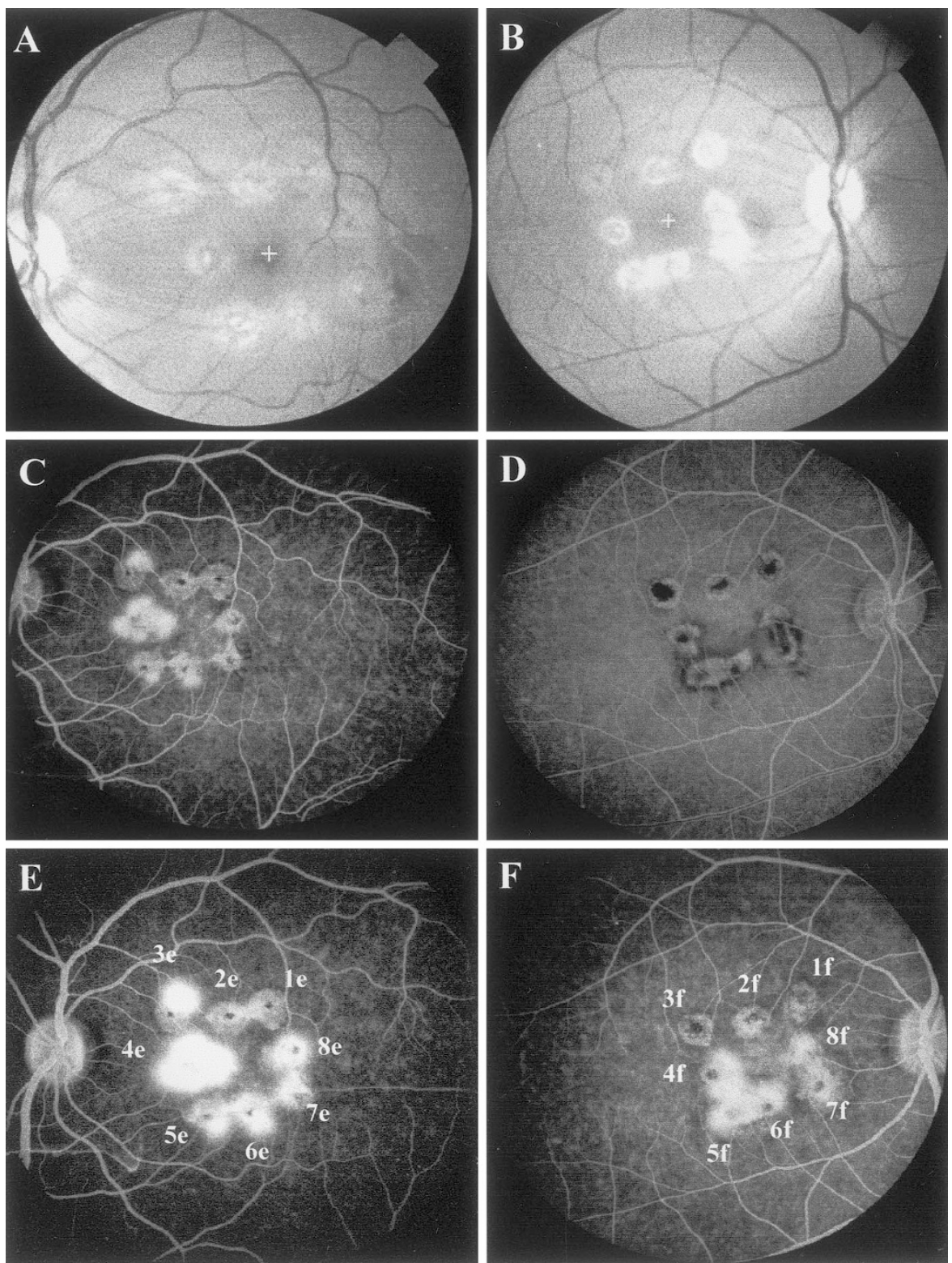

Figure 7.

Fundus photographs (A and B) and fluorescein angiograms (C to F) after IV delivery of $50 \mu \mathrm{l} \mathrm{of} 0.75 \mathrm{nmol} / \mu \mathrm{l}$ DS131 (A, C, and E) and DS135 (B, D, and F). DS131 is a random control phosphorothioate oligonucleotide (PS-oligo) for DS135. DS135 is a PS-oligo targeting VEGF ${ }_{165}$ mRNA upstream of the translation initiation codon. Photographs were taken at early ( $C$ and $D)$ and late $(E$ and $F)$ phases of angiography at 8 weeks after injection. Incomplete inhibition of CNV formation was observed in DS135-treated eyes (B, D, and F). The plus symbols in A and B indicate the central fovea.

though no serious complication was directly attributed to the SR surgery itself, dose-dependent residual fluid and cellular infiltration in the SR space and slight distortion of the neuroretina have been observed. These adverse effects were particularly evident with the highest dose $(50 \mu \mathrm{l}, 0.75 \mathrm{nmol} / \mu \mathrm{l})$, indicating that the volume and concentration of DS135 needs to be further adjusted. Although the cellular infiltration could be minimized by IV use of certain amounts of antiinflammatory drugs (Danis et al, 2000; Flores-Aguilar et al, 1997; Shen et al, 2000), our results may also imply that the undesired side effects of DS135 are associated with the biochemical structure of PS-oligo (Black et al, 1994; Dvorchik and Marquis, 2000). It has been reported that chimeric oligonucleotides consist- ing of a mixed phosphodiester-phosphorothioate backbone and having 2-methoxyrobonucleotides modification, dramatically eliminated the side effects of PS-oligos but retained the effective potency in the central nerve system (Ho et al, 1998). Further modification of the PS-oligos is particularly important for SR delivery because minor cellular inflammation in the central fovea could dramatically impair vision.

Effective inhibition of CNV depends on careful choice of the genes targeted. The VEGF gene was chosen because it is currently the most prominent angiogenic factor associated with the development of CNV (Mousa et al, 1999; Okamoto et al, 1997; Ozaki et al, 1998; Spilsbury et al, 2000). It has been reported that sole overexpression of VEGF by the RPE cells is 

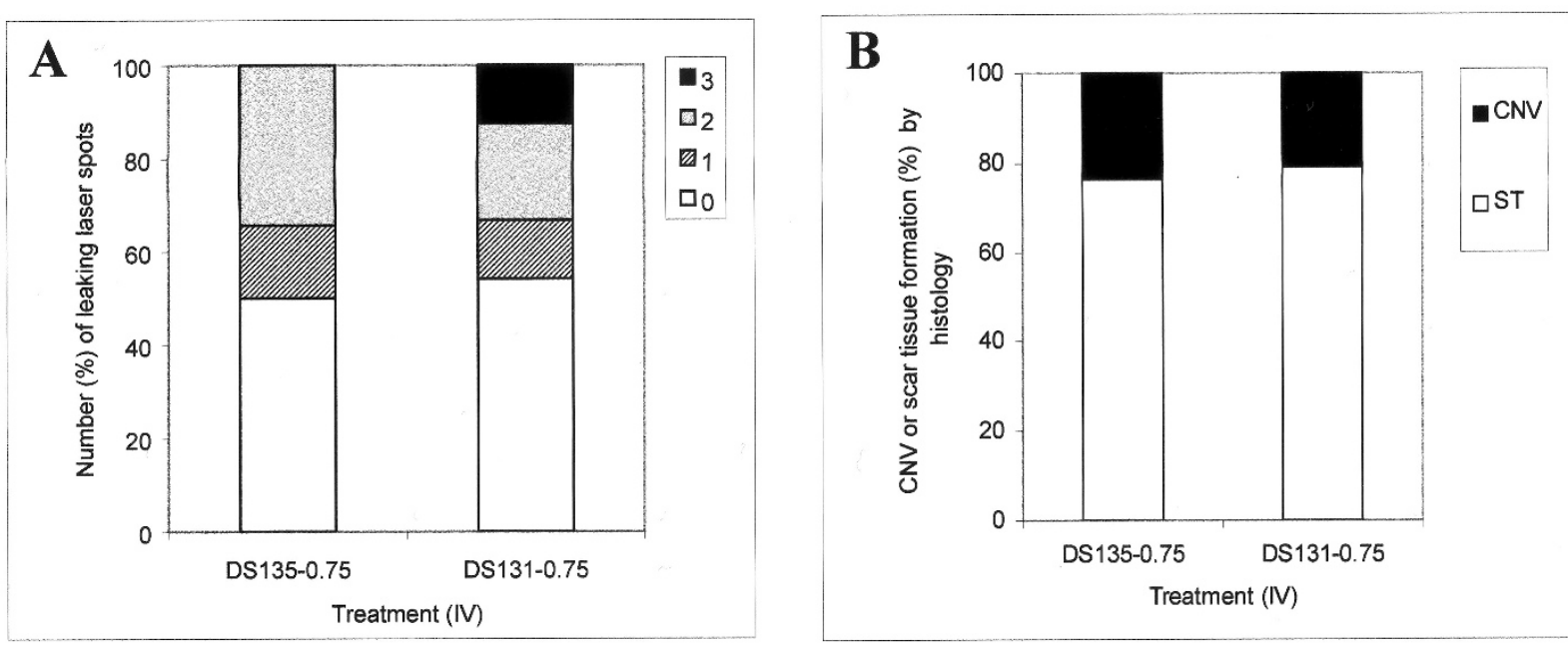

Figure 8.

Effects of DS135 on the development of CNV after IV injection. The development of CNV was quantified by scoring the appearance of laser lesions during fluorescein angiography (FA) (see "Materials and Methods"). Laser spots scoring 2+ or higher were considered as CNV-related lesions. No laser lesions in the DS135-treated group showed strong fluorescein leakage (scores +3 ), but statistical analysis showed no significant difference between the DS135- and DS131-treated groups (Fig. $8 \mathrm{~A}, p=0.09, n=4$ and 3 , respectively). Nor was significant difference achieved when analyzing +2 scores $(p=0.35)$ or taking scores +2 and +3 together $(p$ $=0.93$ ). This tendency was also supported by data obtained from histologic examination (Fig. $8 \mathrm{~B}, p=0.91$ ). $\mathrm{ST}=\mathrm{scar}$ tissue.

sufficient to induce CNV, and suppression of VEGF inhibits the development of neovascularization (Kwak et al, 2000; Ozaki et al, 2000; Schwesinger et al, 2001; Spilsbury et al, 2000). The sequence of DS135 is targeted to the $5^{\prime}$-untranslated region of the VEGF gene, a region defined as an internal ribosome entry site (IRES) (Huez et al, 1998). These large sequences (more than 1000 base pairs) have been identified in a number of proteins and are thought to regulate translation initiation as an alternate mechanism to the cap-dependent process mediated by elements in the $3^{\prime}$-untranslated region. An IRES containing 132 bases immediately upstream of the AUG showed substantially greater efficiency (between 4.4 and 40 times) than the full length of the IRES in VEGF mRNA translation (Stein et al, 1998). The DS135 corresponds to nucleotides 30 to 50 upstream of the AUG start codon and coincides with this region. It is assumed that DS135 binds to the IRES sequence and prevents the complex folding patterns required for efficient ribosome entry (Huez et al, 1998), therefore preventing translation of up-regulated VEGF mRNA. In our own hands, the ability of DS135 to down-regulate VEGF has been demonstrated by Western analysis, ELISA, and quantitative Taqman RT-PCR techniques using the D407 RPE cell line before the efficacy study in the monkey (Garrett et al, 2001). By semiquantified Western blot analysis, DS135 showed a dose-dependent inhibition of VEGF protein production, with $66 \%$ and 93\% reduction of VEGF levels when treated with 1.0 and $5.0 \mu \mathrm{M}$ DS135 in vitro. Furthermore, analysis by ELISA demonstrated a statistically significant reduction in VEGF protein levels with $0.5 \mu \mathrm{M}$ DS135 treatment to approximately $65 \%$ of levels in controls (35\% inhibition) under hypoxic condition, and DS135 significantly suppressed CNV formation in the laserinduced rat CNV model (Garrett et al, 2001). Although DS135 has shown a reduction of CNV formation in the laser-induced CNV model, the inhibitory effect of DS135 on VEGF production in the monkey eye would need to be fully assessed before clinical trial consideration.

The laser-induced CNV has been considered as a reproducible and clinically relevant model, and currently it is the most commonly used CNV model in eye research. Previous investigations have demonstrated a preferential distribution of PS-oligo at laser lesions (Ogata et al, 1999; Shen et al, 1999). The accumulation of PS-oligos at laser lesions might be associated with altered cell membranes with a higher affinity for fusion but most likely reflects the activity of the cells during the development of CNV (Zhang et al, 1993). It has been confirmed that the majority of cells that take up PS-oligo at laser lesions are proliferating RPE, macrophages, and activated choroidal cells, which are also the main sources of overexpression of VEGF in the laser-induced CNV (Ishibashi et al, 1997; Shen et al, 1998; Yi et al, 1997) and in neovascular membranes of humans (Lopez et al, 1996). This coincidentally allows us to specifically deliver DS135 into the cells overexpressing VEGF during the development of CNV.

Despite a promising inhibitory effect of DS135 in the rat (Garrett et al, 2001), the inhibition was incomplete and lacked a statistically significant difference in this particular study in the monkey. There have been several investigations in the use of antisense PSoligos targeting VEGF to inhibit retinal and choroidal neovascularization (Ogata et al, 1999; Robinson et al, 1996). However, data from all previous investigations demonstrated either incomplete or ineffective inhibition (Ogata et al, 1999; Robinson et al, 1996). Incomplete inhibition of CNV by DS135 might indicate that other angiogenic factors are involved in the process of CNV, implying the complexity regarding the pathogenesis of CNV (Mousa et al, 1999; Takahashi et al, 2000). From our own data, we cannot rule out that there is a 

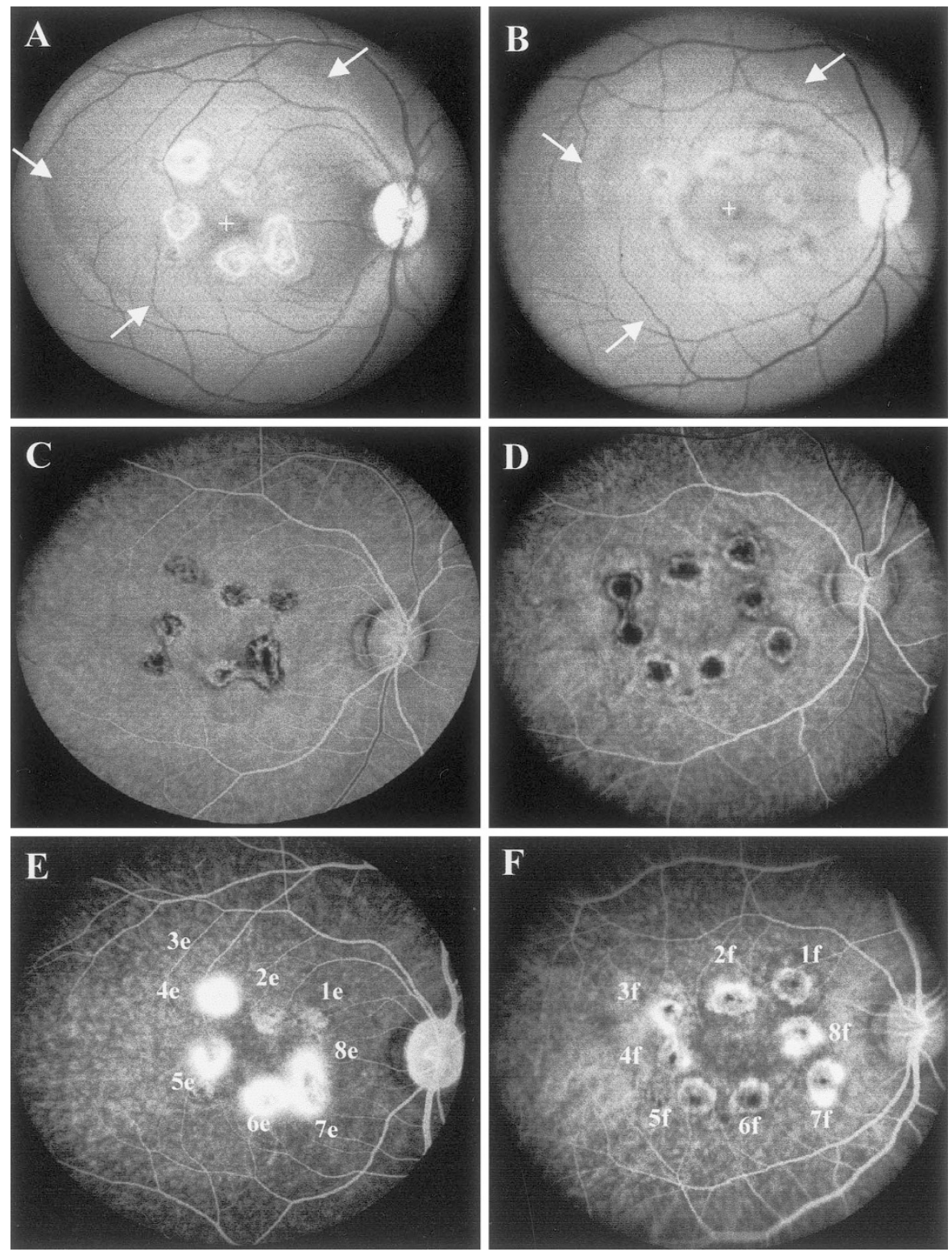

Figure 9 .

Fundus photographs ( $A$ and $B$ ) and fluorescein angiograms ( $C$ to $F$ ) after SR delivery of $50 \mu \mathrm{l}$ of $0.075 \mathrm{nmol} / \mu \mathrm{l}$ DS131 (A, C, and E) and DS135 (B, D, and F), respectively. Fluorescent photographs were taken at early $(C$ and $D)$ and late $(E$ and $F)$ phases of angiography at 8 weeks after injection. Incomplete inhibition of CNV formation was observed in the DS135-treated eye (B, D, and F). The arrows in A and B indicate the area contacted by the injected solution, and the plus symbols indicate the central fovea, respectively.

species difference in drug reaction between the rat and monkey. However, incomplete inhibition might also indicate a low therapeutic index of DS135, suggesting that the targeted sequence and chemistry need further optimization. It would seem that no group to date has been successful in defining an oligonucleotide sequence that completely inhibits VEGF mRNA translation and new vessel formation in the eye or any other system. Although intraocular injection of DS135 at high doses resulted in a high intensity of PS-oligo distribution, the actual therapeutic concentration required in situ is unknown. In addition, our study lacked administration of high doses of DS135 $(50 \mu \mathrm{l}, 7.5 \mathrm{nmol} / \mu \mathrm{l}$ for IV delivery and $0.75 \mathrm{nmol} / \mu$ l for SR injection) for the efficacy test because of the risks of cellular infiltration, vitreous haze, and prolonged iatrogenic macular detachment. Administration of high doses of DS135 might improve the inhibitory effect but might also further complicate the issue of retinal safety.

The predominant methods of determining CNV formation are FA and histologic examination. Since the location of laser lesions is difficult to control on sample embedding and sectioning, direct correlation of the status of individual laser lesions during FA with their histologic changes is extremely labor intensive and technically difficult. In the CNV model of the present study, FA has demonstrated $23 \%$ to $28.6 \%$ of laser lesions showing $2+$ grades or higher of fluorescein leakage during FA in the interval from 2 to 8 weeks after photocoagulation; this corresponded to $22.1 \%$ of 

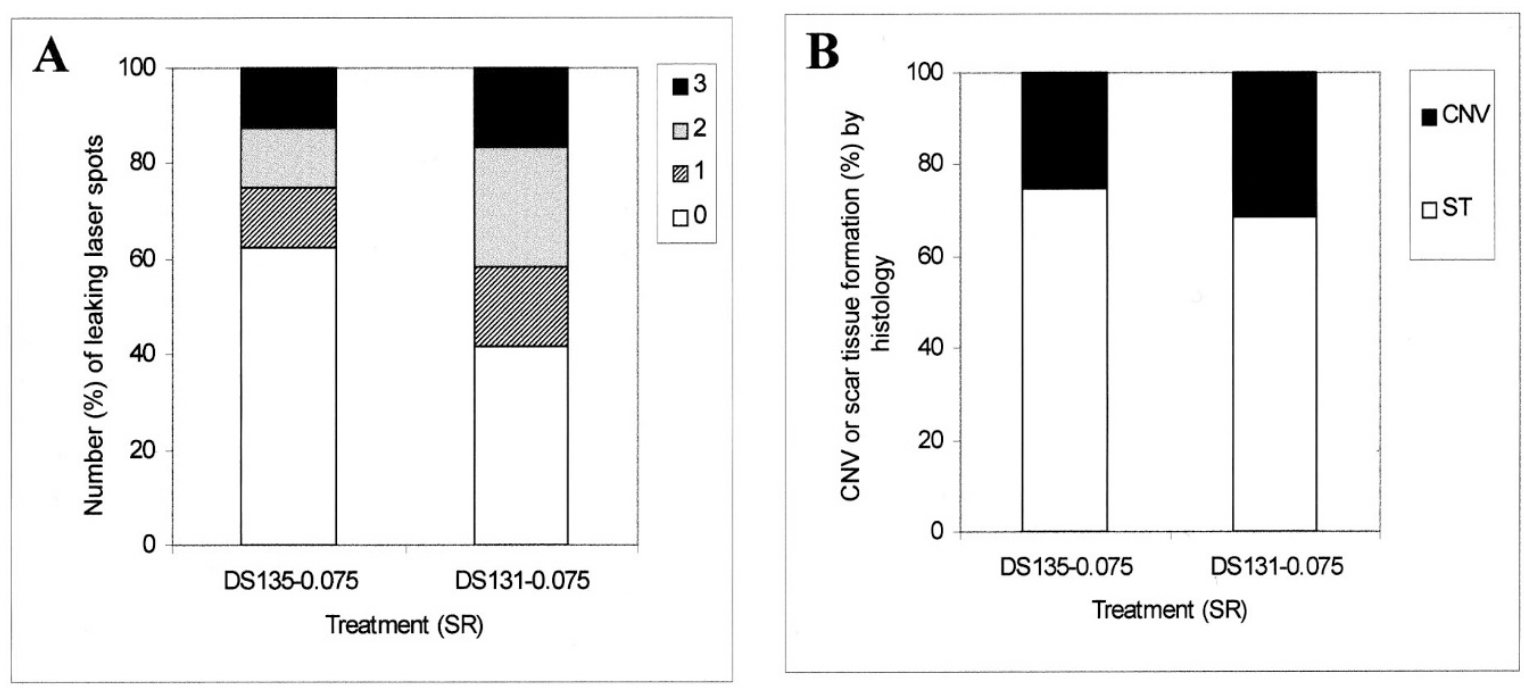

\section{Figure 10.}

Effects of DS135 on the development of CNV after SR injection. The development of CNV was quantified by scoring the appearance of laser lesions during FA (see "Materials and Methods"). Laser spots scoring 2+ or higher were considered as CNV-related lesions. Analysis of the data obtained from FA (A) and histologic examination (B) did not show significant differences between the DS135-treated $(n=2)$ and the DS131-treated $(n=3)$ groups $(p>0.41)$. ST $=$ scar tissue.

histologic CNV by termination at 8 weeks after photocoagulation. After intraocular delivery of DS135 or DS131, $25 \%$ to $42 \%$ of lesions showed $2+$ grades or higher of fluorescein leakage by FA, corresponding to $21.1 \%$ to $31.3 \%$ histologic CNV at termination. Generally, the percentages of CNV determined by FA were higher than those confirmed by histologic examination, indicating that the lesions with +2 or higher scores of fluorescein leakage actually involved certain laser spots that formed scar tissue rather than CNV development (Figs. 8 and 10). The protocol used in this study has been reported to result in $40 \%$ incidence of CNV-related fluorescein leakage (Ryan, 1979). In our particular case, in addition to a lower rate (around $30 \%$ ) of CNV formation, our data also demonstrated dramatic variations in CNV development among individual eyes, indicating a potential limitation of this monkey model for statistical evaluation of antiangiogenic therapy. According to a previous investigation, the rate of laser-induced CNV in the monkey also varied dramatically, with the highest rate when laser spots were delivered around the macula (Ryan, 1979). Data from our histologic examination revealed that up to $41.7 \%$ of laser lesions had an intact Bruch's membrane, indicating a higher laser energy damage is required to improve the success rate of CNV. With the current protocol for laser photocoagulation, however, $23 \%$ ( 6 of 26 eyes) of eyes have been excluded from the data analysis because of massive SR hemorrhage induced by laser photocoagulation. The massive SR hemorrhage usually resulted in scar tissue formation rather than the development of CNV. In addition, the SR hemorrhage or excessive exudation after photocoagulation made SR injection extremely difficult, with the result that a macular hole was usually induced and the injected solution leaked into the vitreous cavity.

After intense laser photocoagulation, around 50\% to $80 \%$ of lesions developed CNV in the rat model
(Garrett et al, 2001; Shen et al, 1998). Intravitreal administration of DS135 has shown 50\% inhibition of CNV formation in the rat eye when approximately 20 eyes per group were used to achieve a statistically significant difference $(p<0.002$, Garrett et al, 2001). Comparing the relative volume of the vitreous, the effective DS135 concentration after IV injection of a high dose of DS135 in the present study is very close to that used in the rat experiment. Based on the 30\% to $40 \%$ success rate in the monkey CNV model, a computerized power calculation indicates that at least 25 eyes per group would be required to satisfy a statistically significant difference (Mendoza and Stafford, 2001; Dr. Jorge L. Mendoza, University of Oklahoma, personal communication, 2001). This sample size estimation was based on the assumption that VEGF is the sole angiogenic factor responsible for the development of CNV in the eye. In the future, the monkey CNV model could be improved by using higher laser energy. Laser spots should be delivered around the macula with an increased distance from the central fovea, thus decreasing the occurrence of SR hemorrhage. The fixed laser protocol should be replaced by adjusting the laser energy (power density and duration) to achieve SR heating bleb formation (indicating a break of the Bruch's membrane). Considering the similarity between human and monkey eyes, this study has presented essential information for clinical trial consideration. There might be hope for a statistically significant inhibition provided the monkey CNV model is improved and the targeted oligonucleotide sequence as well as the in vivo doses are further optimized.

\section{Materials and Methods}

\section{Oligonucleotide Design and Synthesis}

Two PS-oligos, DS135 (5'GAGCCGGAGAGGGAGCGCGA; targeting both human and rat VEGF 165 
genes upstream of the translation initiation codon) and DS131 (5'AGGACCTGTCAATTCCGGTG; a random control with no known homology to any sequence currently available in the genome database), were synthesized commercially by Proligo (Boulder, Colorado), purified with HPLC, and tested for toxicology. The DS135 has the same oligonucleotide sequence as that used in a rat experiment (DS085; Garrett et al, 2001). To assess cellular uptake and persistence of PS-oligo in the retina, a fluorescent-labeled DS135 compound was synthesized on an ABI Model 392 DNA synthesizer (ABI, Foster City, California) with 6-FAM (ABI-Foster City) conjugated to the 5' terminal nucleotide. The FL-DS135 was purified by anion exchange, and the concentrations of all PS-oligos were determined by optical density at $260 \mathrm{~nm}$ as reported previously (Garrett et al, 2001; Shen et al, 1999).

\section{Animal Preparation and Anesthesia}

Twenty-eight rhesus monkeys ranging in age from 4 to 6 years and weighing between 6 and $8 \mathrm{~kg}$ were used in accordance with the ARVO Statement on the Use of Animals in Vision and Ophthalmic Research. The animals were anesthetized with intravenous thiopantlum natricum at a concentration of $25 \mathrm{mg} / \mathrm{ml}$, with a first dose of $15 \mathrm{mg} / \mathrm{kg}$. A trained anesthetic technician monitored the airway, respiration, and pulse during the injection. Anesthesia was maintained by intermittent intravenous supplements. Topical anesthesia was supplemented by $0.5 \%$ Decaine drops. Pupils were dilated with $2.5 \%$ phenylephrine and $1 \%$ tropicamide drops.

\section{Microdelivery System and Intravitreal and Subretinal Injections}

A custom-made microdelivery system consisted of a 100- $\mu$ l Hamilton syringe, a 10-cm connecting thickwalled silicon tube with external and internal diameters of 1.0 and $0.5 \mathrm{~mm}$, respectively, and a 20-gauge glass pipette of $8-\mathrm{cm}$ length drawn out to a tip diameter of $120 \mu \mathrm{m}$. The tip was curved at 120 degrees and beveled to facilitate penetration of the retina. All surgical procedures were performed under full aseptic conditions. The conjunctiva was opened from superior nasal to inferior temporal for intraocular injection. After careful cautery of blood vessels on the scleral surface, two ports were made with a 20-gauge V-lance at clock locations 1:30 and 10:30 through the pars plana. A 20-gauge fiberoptic probe was inserted into one port for endoillumination and another port was used for glass micropipette insertion. Intravitreal injection was a one-stage procedure. The tip of the glass pipette was gently and slowly advanced to the macular surface, and the solution was injected as close to the retinal surface as possible. For SR injection, a site was selected $500 \mu \mathrm{m}$ superior to the fovea, avoiding visible retinal blood vessels. The tip of the micropipette was gently advanced at an oblique angle through the retina, trying not to disturb the underlying pigment epithelium. Once the tip was visible under the retina, the second assistant slowly injected 10 to $20 \mu \mathrm{l}$ of solution to achieve a SR bleb of about $1000-\mu \mathrm{m}$ diameter. Then the tip of the glass pipette was advanced to the edge of the precreated SR bleb, and the second assistant slowly finished the injection. After delivery of $50 \mu \mathrm{l}$ of solution, the microdelivery system and the fiberoptic tube were withdrawn and the sclerotomies immediately plugged. The sclerotomies were closed by 7-0 nylon sutures and the conjunctival flaps repositioned. A mixture of gentamicin $(2 \mathrm{mg})$ and dexamethasone $(2.5 \mathrm{mg})$ was injected under the inferior conjunctiva. Atropine (1\% ointment) and tetracycline $(0.5 \%$ ointment) were applied to the conjunctival sac and the eyelids taped closed.

\section{Model of CNV and Intraocular Delivery of PS-Oligos}

Intense argon laser photocoagulation was performed to create a model of CNV as previously described (Ryan, 1979). Briefly, eight laser spots were applied around the macula of each eye in the manner of a grid with a protocol of $700 \mathrm{~mW}$ power intensity, $100 \mu \mathrm{m}$ spot size, and 0.1 s duration. The distance from each laser spot to the central fovea was 0.5 to 1.0 disc diameter size. Care was taken to avoid damaging the fovea. On the day after laser photocoagulation, $50 \mu \mathrm{l}$ of test solution was injected intravitreally or subretinally to cover the photocoagulated area using the techniques described above.

\section{Ophthalmic Examinations and FA}

For the eyes used in toxicity study (Table 1), fundus photography was taken at 1 and 3 weeks to monitor changes of the retina. For those animals treated by laser photocoagulation that subsequently underwent IV or SR injection, fundus photography and FA were performed at 8 weeks after treatment to monitor the fundus changes and the CNV development. FA was performed by intravenous injection of $10 \%$ fluorescein sodium, $0.1 \mathrm{ml} / \mathrm{kg}$ of body weight. Identification of CNV was based on fluorescein behavior through the phases of angiogram from 20 seconds to 10 minutes after dye injection. The status of laser spots during FA was graded in a masked fashion by two examiners using reference angiograms, and the scores were recorded as follows: 0, no fluorescein staining; $1+$, slight fluorescein staining; $2+$, moderate fluorescein leakage; and $3+$, prominent fluorescein leakage or pooling. When two scores for a lesion did not coincide, the higher score was used. The appearance of CNV was characterized by continuous fluorescein leakage or pooling during FA. Laser spots scored 2+ or higher were considered to be related to the development of CNV.

\section{Reduction of Lipofuscin-Like Autofluorescence and Confocal Laser Scanning Microscopy}

After fundus photography, eyes receiving FL-DS135 and BSS were enucleated at 1 and 3 weeks after injection (Table 1) and the macula was marked with India ink. Eyes were snap-frozen in optimal cutting 
temperature compound using a $50-\mathrm{ml}$ centrifuge tube and stored at $-80^{\circ} \mathrm{C}$ for cryosectioning. Cryosections of 12 - to $14-\mu \mathrm{m}$ thickness were cut at $-20^{\circ} \mathrm{C}$ (Jung Frigocut $2800 \mathrm{~N}$ Cryostat, Leica, Germany). Considering that the presence of lipofuscin-like autofluorescence in the retina complicates the use of fluorescent microscopy, autofluorescence (mainly caused by lipofuscin granules in the RPE) was blocked by a specially developed procedure consisting of incubating the cryosections with $0.5 \%$ Sudan Black B in $70 \%$ ethanol for 17 minutes before confocal laser scanning microscopy.

\section{Histologic Evaluation}

At 3 and 8 weeks after oligo delivery, followed by fundus photography and FA, the animals that received unlabeled PS-oligos were euthanized and their eyes were enucleated and processed for paraffin embedding (Table 1). These eyes were fixed in 4\% paraformaldehyde- $0.25 \%$ glutaraldehyde in $0.1 \mathrm{~m}$ PBS for 3 days. Paraffin-embedded sections of $5-\mu \mathrm{m}$ thickness were cut to assess the retinal toxicology after IV or SR injection of DS135. For the eyes used for efficacy study, serial sections were collected when the first laser lesion was recognized. This resulted in 100 to 120 slides from each eye, with three sections on each slide. Hematoxylin and eosin staining was performed every 20 slides to determine the development of CNV after laser photocoagulation and PS-oligo treatment (DS135 or DS131).

\section{Statistical Evaluation}

Independent sample $t$ tests were used to compare mean score and percentage of CNV-related fluorescein leaking laser spots (scores 2+ or higher) and the rate of histologic CNV in DS135 and the dose control DS131-treated eyes. Statistical significance was defined as $p<0.05$.

\section{Acknowledgements}

The authors thank Miss Tammy Zaknich for histologic preparations, Ms. Shu-Yi Han for fundus photography, and Dr. Anthony Kicic for proofreading of this manuscript. Also, the authors acknowledge Dr. Jorge L. Mendoza, Psychology Department, University of Oklahoma, Norman, Oklahoma, for the power calculation using a customer-designed computer package.

\section{References}

Black LE, Farrelly JG, Cavagnaro JA, Ahn CH, Degeorge JJ, Taylor AS, Defelice AF, and Jordan A (1994). Regulatory considerations for oligonucleotide drugs: Updated recommendations for pharmacology and toxicology studies. Antisense Res Dev 4:299-301.

Bressler NM, Bressler SB, and Fine SL (1988). Age-related macular degeneration. Surv Ophthalmol 32:375-413.

Campochiaro PA (2000). Retinal and choroidal neovascularization. J Cell Physiol 184:301-310.
Danis RP, Ciulla TA, Pratt LM, and Anliker W (2000). Intravitreal triamcinolone acetonide in exudative age-related macular degeneration. Retina 20:244-250.

Detrick B (2001). Inhibition of human cytomegalovirus replication in a human retinal epithelial cell model by antisense oligonucleotides. Invest Ophthalmol Vis Sci 42:163-169.

Dvorchik BH and Marquis JK (2000). Disposition and toxicity of a mixed backbone antisense oligonucleotide, targeted against human cytomegalovirus, after intravitreal injection of escalating single doses in the rabbit. Drug Metab Dispos 28:1255-1261.

Flores-Aguilar M, Besen G, Vuong C, Tatebayashi M, Munguia D, Gangan P, Wiley CA, and Freeman WR (1997). Evaluation of retinal toxicity and efficacy of anticytomegalovirus and anti-herpes simplex virus antiviral phosphorothioate oligonucleotides ISIS 2922 and ISIS 4015. $\mathrm{J}$ Infect Dis 175:1308-1316.

Fong DS (2000). Photodynamic therapy with verteporfin for age-related macular degeneration. Ophthalmology 107: 2314-2317.

Garrett KL, Shen WY, and Rakoczy PE (2001). In vivo use of oligonucleotides to inhibit choroidal neovascularisation in the eye. J Gene Med 3:373-383.

Hangai M, Tanihara H, Honda $Y$, and Kaneda $Y$ (1998). In vivo delivery of phosphorothioate oligonucleotides into murine retina. Arch Ophthalmol 116:342-348.

Ho SP, Livanov V, Zhang W, Li JH, and Lesher T (1998). Modification of phosphorothioate oligonucleotides yields potent analogs with minimal toxicity for antisense experiments in the CNS. Mol Brain Res 62:1-11.

Huez I, Creancier L, Audigier S, Gensac MC, Prats AC, and Prats $H$ (1998). Two independent internal ribosome entry sites are involved in translation initiation of vascular endothelial growth factor mRNA. Mol Cell Biol 18:6178-6190.

Husain D, Kramer M, Kenny AG, Michaud N, Flotte TJ, Gragoudas ES, and Miller JW (1999). Effects of photodynamic therapy using verteporfin on experimental choroidal neovascularization and normal retina and choroid up to 7 weeks after treatment. Invest Ophthalmol Vis Sci 40:23222331.

Ishibashi T, Hata Y, Yoshikawa H, Nakagawa K, Sueishi K, and Inomata H (1997). Expression of vascular endothelial growth factor in experimental choroidal neovascularization. Graefes Arch Clin Exp Ophthalmol 235:159-167.

Kwak N, Okamoto N, Wood JM, and Campochiaro PA (2000). VEGF is major stimulator in model of choroidal neovascularization. Invest Ophthalmol Vis Sci 41:3158-3164.

Leeds JM, Henry SP, Bistner S, Scherrill S, Williams K, and Levin AA (1998). Pharmacokinetics of an antisense oligonucleotide injected intravitreally in monkeys. Drug Metab Dispos 26:670-675.

Leeds JM, Henry SP, Truong L, Zutshi A, Levin AA, and Kornbrust D (1997). Pharmacokinetics of a potential human cytomegalovirus therapeutic, a phosphorothioate oligonucleotide, after intravitreal injection in the rabbit. Drug Metab Dispos 25:921-926.

Lip PL, Belgore F, Blann AD, Hope-Ross MW, Gibson JM, and Lip GYH (2000). Plasma VEGF and soluble VEGF receptor FLT-1 in proliferative retinopathy: Relationship to endothelial dysfunction and laser treatment. Invest Ophthalmol Vis Sci 41:2115-2119. 
Lopez PF, Sippy BD, Lambert HM, Thach AB, and Hinton DR (1996). Transdifferentiated retinal pigment epithelial cells are immunoreactive for vascular endothelial growth factor in surgically excised age-related macular degeneration-related choroidal neovascular membranes. Invest Ophthalmol Vis Sci 37:855-868.

Mendoza JL and Stafford KL (2001). Confidence intervals, power calculation, and sample size estimation for the squared multiple correlation coefficient under the fixed and random regression models: A computer program and useful standard tables. Educ Psychol Meas 61:650-667.

Michaelson IC (1948). The model of development of vascular system of the retina, with some observation on its significance for certain retinal disease. Trans Ophthalmol Soc UK 68:137-180.

Mousa SA, Lorelli W, and Campochiaro PA (1999). Role of hypoxia and extracellular matrix-integrin binding in the modulation of angiogenic growth factors secretion by retinal pigmented epithelial cells. J Cell Biochem 74:135-143.

Ogata N, Otsuji T, Matsushima M, Kimoto T, Yamanaka R, Takahashi K, Wada M, Uyama M, and Kaneda Y (1999). Phosphorothioate oligonucleotides induction into experimental choroidal neovascularization by HVJ-liposome system. Curr Eye Res 18:261-269.

Okamoto N, Tobe T, Hackett SF, Ozaki H, Vinores MA, Larochelle W, Zack DJ, and Campochiaro PA (1997). Transgenic mice with increased expression of vascular endothelial growth factor in the retina: a new model of intraretinal and subretinal neovascularization. Am J Pathol 151:281-291.

Ozaki H, Okamoto N, Ortega S, Chang M, Ozaki K, Sadda S, Vinores MA, Derevjanik N, Zack DJ, Basilico C, and Campochiaro PA (1998). Basic fibroblast growth factor is neither necessary nor sufficient for the development of retinal neovascularization. Am J Pathol 153:757-765.

Ozaki H, Okamoto N, Ortega S, Chang M, Ozaki K, Sadda S, Vinores MA, Ozaki H, Seo MS, Ozaki K, Yamada H, Yamada E, Okamoto N, Hofmann F, Wood JM, and Campochiaro PA (2000). Blockade of vascular endothelial cell growth factor receptor signaling is sufficient to completely prevent retinal neovascularization. Am J Pathol 156:697-707.

Rakoczy PE, Lai MC, Watson M, Seydel U, and Constable IJ (1996). Targeted delivery of an antisense oligonucleotide in the retina: Uptake, distribution, stability, and effect. Antisense Nucleic Acid Drug Dev 6:207-213.

Robinson GS, Pierce EA, Rook SL, Foley E, Webb R, and Smith LEH (1996). Oligodeoxynucleotides inhibit retinal neovascularization in a murine model of proliferative retinopathy. Proc Nat Acad Sci USA 93:4851-4856.

Ryan SJ (1979). The development of an experimental model of subretinal neovascularization in disciform macular degeneration. Trans Am Ophthalmol Soc 77:707-745.

Schwesinger C, Yee C, Rohan RM, Joussen AM, Fernandez A, Meyer TN, Poulaki V, Ma JJK, Redmond TM, Liu SY, Adamis AP, and D'Amato RJ (2001). Intrachoroidal neovascularization in transgenic mice overexpressing vascular endothelial growth factor in the retinal pigment epithelium. Am J Pathol 158:1161-1172.

Shen WY, Constable IJ, Chelva E, and Rakoczy PE (2000). Inhibition of diclofenac formulated in hyaluronan on angiogenesis in vitro and its intraocular tolerance in the rabbit eye. Graefes Arch Clin Exp Ophthalmol 238:273-282.
Shen WY, Garrett KL, Da Cruz L, Constable IJ, and Rakoczy PE (1999). Dynamics of phosphorothioate oligonucleotides in normal and laser photocoagulated retina. $\mathrm{Br} \mathrm{J}$ Ophthalmol 83:852-861.

Shen WY, Yu MJT, Barry CJ, Constable IJ, and Rakoczy PE (1998). Expression of cell adhesion molecules and vascular endothelial growth factor in experimental choroidal neovascularisation in the rat. $\mathrm{Br} \mathrm{J}$ Ophthalmol 82:1063-1071.

Shiraga F, Takasu I, and Shiragami C (1998). Treatment options in subfoveal choroidal neovascularization secondary to age-related macular degeneration. Sem Ophthalmol 13: 31-39.

Sone H, Kawakami Y, Kumagai AK, Oduka Y, Sekine Y, Honmura S, Segawa T, Suzuki H, Yamashita K, and Yamada $N$ (1999). Effects of intraocular or systemic administration of neutralizing antibody against vascular endothelial growth factor on the murine experimental model of retinopathy. Life Sci 65:2573-2580.

Spilsbury K, Garrett KL, Shen WY, Constable IJ, and Rakoczy PE (2000). Overexpression of vascular endothelial growth factor (VEGF) in the retinal pigment epithelium leads to the development of choroidal neovascularization. Am J Pathol 157:135-144.

Stein CA and Cheng YC (1993). Antisense oligonucleotides as therapeutic agents: Is the bullet really magical? Science 261:1004-1012.

Stein I, Itin A, Einat P, Slaliter R, Grossman Z, and Keshet E (1998). Translation of vascular endothelial growth factor mRNA by internal ribosome entry: Implications for translation under hypoxia. Mol Cell Biol 18:3112-3119.

Stone TW and Jaffe GJ (2000). Reversible bull's-eye maculopathy associated with intravitreal fomivirsen therapy for cytomegalovirus retinitis. Am J Ophthalmol 130:242-243.

Submacular Surgery Trials Pilot Study (2000a). Submacular surgery trials randomized pilot trial of laser photocoagulation versus surgery for recurrent choroidal neovascularization secondary to age-related macular degeneration: I. Ophthalmic outcomes: Submacular surgery trials pilot study report number 1. Am J Ophthalmol 130:387-407.

Submacular Surgery Trials Pilot Study (2000b). Submacular Surgery Trials randomized pilot trial of laser photocoagulation versus surgery for recurrent choroidal neovascularization secondary to age-related macular degeneration: II. Quality of life outcomes: Submacular Surgery Trials Pilot Study Report Number 2. Am J Ophthalmol 130:408-418.

Takahashi T, Nakamura T, Hayashi A, Kamei M, Nakabayashi M, Okada AA, Tomita N, Kaneda Y, and Tano Y (2000). Inhibition of experimental choroidal neovascularization by overexpression of tissue inhibitor of metalloproteinases- 3 in retinal pigment epithelium cells. Am J Ophthalmol 130:774-781.

Yi X, Ogata N, Komada M, Yamamoto C, Takahashi K, Omori $\mathrm{K}$, and Uyama M (1997). Vascular endothelial growth factor expression in choroidal neovascularisation in rats. Graefe's Arch Clin Exp Ophthalmol 235:313-319.

Young RW (1987). Pathophysiology of age-related macular degeneration. Surv Ophthalmol 31:291-306.

Zhang NL, Samadani EE, and Frank RN (1993). Mitogenesis and retinal pigment epithelial cell antigen expression in the rat after krypton laser photocoagulation. Invest Ophthalmol Vis Sci 34:2412-2424. 